\title{
(2) OPEN ACCESS \\ Tolosa-Hunt syndrome relapse during pregnancy following chronic intake of combined oral contraceptives
}

\author{
Bernadeth Lyn Cal Piamonte $\quad$ (1) , Keno Lorenzo Ong, ${ }^{2}$ Alvin Rae Cenina ${ }^{1}$
}

'Department of Neurosciences, College of Medicine and Philippine General Hospital, University of the Philippines Manila, Manila, Metro Manila, Philippines

${ }^{2}$ Department of Obstetrics and Gynecology, College of Medicine and Philippine General Hospital, University of the Philippines Manila, Manila, Metro Manila, Philippines

Correspondence to

Dr Bernadeth Lyn Cal Piamonte; bcpiamonte@gmail.com

Accepted 23 December 2020

Check for updates

(c) BMJ Publishing Group Limited 2021. Re-use permitted under CC BY-NC. No commercial re-use. See rights and permissions. Published by BMJ.

To cite: Piamonte BLC Ong KL, Cenina AR. BMJ Case Rep 2021:14:e238944. doi:10.1136/bcr-2020238944

\section{SUMMARY}

Tolosa-Hunt syndrome (THS) is a rare syndrome of painful ophthalmoplegia secondary to an idiopathic granulomatous inflammation affecting the cavernous sinus, superior orbital fissure or orbit. Pregnancy and pregnancy-related hormones have been identified as potential triggers. A 39-year-old gravida-2 para-1 woman with prior chronic intake of combined oral contraceptives (COC) suffered two episodes of painfu ophthalmoplegia - the first event with spontaneous remission and the relapse occurring during pregnancy and with complete resolution following steroid treatment. MRI revealed a postinflammatory mass at the junction of the left orbital apex and anterior cavernous sinus, supporting the diagnosis of THS. To our knowledge, this is the first report of a THS relapse occurring during pregnancy following a chronic history of COC intake. This case adds to the growing evidence supporting the relationship between immune and hormonal factors that may be present during pregnancy and the disease pathogenesis of THS.

\section{BACKGROUND}

Tolosa-Hunt syndrome (THS) is a rare condition characterised by painful ophthalmoplegia attributed to an idiopathic granulomatous inflammation of the cavernous sinus, superior orbital fissure or orbit. ${ }^{1}$ It has an estimated incidence of nearly one to two cases per million per year and is ultimately a diagnosis of exclusion. ${ }^{2}$ While its aetiology remains unknown, few reports in the literature have documented its dysimmune pathogenesis influenced by pregnancy and pregnancy-related hormones. ${ }^{34}$

\section{CASE PRESENTATION}

A 39-year-old gravida-2 para-1 woman with a known history of hypertension presented at our institution pregnant at $312 / 7$ weeks of gestation with suddenonset, moderate-to-severe left temporal headache radiating to the orbital-periorbital area with ipsilateral abduction deficit, binocular diplopia, tearing and blurring of vision. This occurred following a chronic history of combined oral contraceptive (COC) intake containing ethinyl oestradiol and levonorgestrel for 7 years. She reported a similar event of painful ophthalmoplegia that occurred 2 years earlier that spontaneously resolved 6 weeks after symptom onset. Examination at the time of admission revealed left esotropia, left lateral rectus palsy and elevated blood pressures. Visual function and fundus examination demonstrated bilateral error of refraction and grade II hypertensive retinopathy. There was no objective sensory deficit on the left side of the face, proptosis or signs of Horner syndrome. Temporary and slight relief of pain was reported with normalisation of blood pressure and administration of intramuscular dexamethasone given for fetal lung maturity. However, the patient's ophthalmoplegia did not improve.

\section{INVESTIGATIONS}

Initial workup revealed an elevated erythrocyte sedimentation rate of $60 \mathrm{~mm} /$ hour, mild leucocytosis of $15.50 \times 10^{9} / \mathrm{L}$ on complete blood count and proteinuria of more than $0.3 \mathrm{~g}$ on 24 -hour urine protein measurement. Baseline serum electrolytes and coagulation profile were normal. Cerebrospinal fluid (CSF) studies, which included aerobic cultures, cytology, and tests for fungal and tuberculous infections, were unremarkable. Thyroid function tests were normal and antidouble stranded DNA and anticonnective tissue disease antibody tests were negative. Screening for diabetes mellitus with glycated haemoglobin and fasting blood sugar was unremarkable. Serum and CSF rapid plasma reagin results to screen for syphilis were normal. Brain MRI showed a small, T1 hyperintense, T2/ fluid-attenuated inversion recovery isointense soft tissue focus with minimal gadolinium enhancement at the junction of the left orbital apex and anterior cavernous sinus, compatible with granulomatous inflammation (figure 1). The left orbit was also oriented medially and there was atrophy of the left lateral rectus muscle. MR angiography was unremarkable, other than a hypolastic/absent A1 segment of the right anterior cerebral artery, which may be a normal anatomical variant.

\section{DIFFERENTIAL DIAGNOSIS}

The diagnosis of THS was based on the unilateral orbital-periorbital headache developing with a paresis of the ipsilateral sixth cranial nerve, granulomatous inflammation at the junction of the orbital apex and anterior cavernous sinus demonstrated by MRI, and absence of other clinical or radiographic signs or symptoms fulfilling the International Classification of Headache Disorders. ${ }^{5}$ Vascular aetiologies, such as a carotid aneurysm or diabetic or arteritic infarction, as differential diagnoses were less likely based on cranial imaging and negative screening tests for diabetes mellitus. Infectious causes, such as focal abscesses, syphilitic pachymeningitis or tuberculous meningoencephalitis, were 


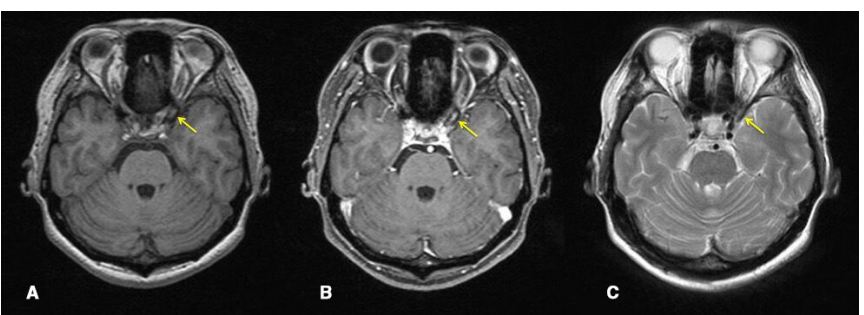

Figure 1 (A) T1-weighted non-contrast, (B) T1-weighted contrast and (C) T2-weighted brain MRI images in axial cuts showing the postinflammatory mass lesion (arrow) at the junction of the left orbital apex and anterior cavernous sinus. Images were generated using a gadolinium-based contrast agent.

ruled out due to the absence of characteristic meningeal signs or systemic signs of infection as well as the unremarkable blood and CSF findings. Neoplasms, such as lymphoma, meningioma or nasopharyngeal carcinoma, were considered but ruled out due to uncharacteristic cranial imaging coupled with negative CSF findings. Moreover, the lack of orbital signs pointing to a mechanical restriction, such as in thyroid orbitopathy or orbital pseudotumor, and negative thyroid function tests rule out these considerations. Based on her elevated blood pressure and total urine protein, the patient was also managed obstetrically as a case of chronic hypertension with superimposed pre-eclampsia with severe features.

\section{TREATMENT, OUTCOME AND FOLLOW-UP}

Labour was induced, and due to a non-reassuring fetal status, an uncomplicated caesarean delivery followed. After delivery, the patient completed prednisone $80 \mathrm{mg}$ daily dose for 3 days, with gradual down-tapering by $20 \mathrm{mg}$ every 2 weeks thereafter; this resulted in progressive alleviation and subsequent complete resolution of the patient's headache and ophthalmoplegia after 5 weeks. On follow-up after 6 months, there was no reported recurrence.

\section{DISCUSSION}

THS is characterised by a non-specific lymphoplasmacytic inflammation of the septa and wall of the cavernous sinus, associated with proliferation of fibroblasts, epithelioid cells and occasional giant cells. ${ }^{67}$ The exact cause of this inflammatory process remains unknown. There seems to be no consistent link to an infectious organism. ${ }^{8}$ Few associations with other inflammatory disorders, such as systemic lupus erythematosus (SLE), Hashimoto thyroiditis, Hodgkin lymphoma and rheumatoid polyarthritis, have been reported; hence, an autoimmune aetiology has been suggested, but is still unclear. ${ }^{9}$ Traumatic injury has also been associated as a potential trigger for THS. ${ }^{10}$ To date, only two cases of THS occurring during pregnancy have been reported in the literature. Levin and Karussis (2002) first reported a 32-year-old woman with two episodes of THS, both of which were linked to changes in gonadal hormone levels-the onset triggered by clomiphene treatment and the relapse triggered by progesterone treatment during pregnancy. ${ }^{4}$ A second report by Litwin and Leung (2017) described a case of a 24-year-old woman who presented with THS during pregnancy following progesterone administration for first-trimester bleeding. ${ }^{3}$

Virtually every organ system undergoes changes during pregnancy, including the immune system. These immune responses contribute to the outcome of pregnancy and to disease pathogenesis as well. ${ }^{11}$ The complex tolerance that exists at the maternal-fetal interface is in part due to the physiological suppression of various immunological functions. ${ }^{12}$ During pregnancy, there is a functional shift of CD4 T lymphocyte subpopulations towards $\mathrm{T}$ helper cells (Th)2-mediated immunity and an increased secretion of the Th2 cytokines-interleukin (IL) 4, IL-10, IL-13. ${ }^{4}$ Therefore, while suppression of Th1-mediated immunity is an important anti-inflammatory component of pregnancy, promotion of antibody-based immunity by Th2 cytokines has resulted in flares of autoimmune diseases mediated mainly by autoantibodies, such as SLE. ${ }^{12}$

Pregnancy-related hormones also exert immunological changes. Progesterone has been shown to inhibit the development of Th1 immune responses and promote Th2 cytokine secretion. ${ }^{1113}$ The differential effects of oestrogen are partly determined by its concentration: low or physiological doses of oestradiol promote Th1 responses and enhance secretion of proinflammatory cytokines (eg, IL-1, IL-6 and tumour necrosis factor- $\alpha$ (TNF- $\alpha)$ ), whereas high or pregnancy doses augment Th2 responses and reduce the production of these cytokines. ${ }^{11}$ With reduced expression of TNF- $\alpha$, which could be neurotoxic, oestrogen offers a neuroprotective effect. ${ }^{14}$ Interestingly, however, attenuation of TNF- $\alpha$ by pregnancy-levels of oestrogen and progesterone has also been shown to further promote granuloma formation by decreasing TNF-induced-apoptosis of granuloma cells. ${ }^{15}$ The shielding effect of these hormones, along with their enhanced expression of angiogenic factors, implicates their importance in the pathogenesis of uncontrolled inflammation and may prove relevant in the pathogenesis of THS. ${ }^{315}$

In this patient, the chronic administration of combined oestrogen and progesterone on top of the immunomodulating effects of pregnancy could have precipitated her episodes of THS. To our knowledge, this is the first report of a THS relapse occurring during pregnancy following a chronic history of COC intake. This case adds to the growing evidence supporting the interplay between immune and hormonal factors and the disease pathogenesis of THS.

\section{Learning points}

- Pregnancy and pregnancy-related hormones have been identified as potential triggers of Tolosa-Hunt syndrome (THS).

- Immune response during pregnancy contributes to disease pathogenesis.

- Oestrogen and progesterone may prove relevant in the pathogenesis of THS.

Contributors BLCP: Research project: conception, organisation, execution. Manuscript preparation: writing of the first draft. KLO and ARC: Manuscript preparation: review and critique.

Funding The authors have not declared a specific grant for this research from any funding agency in the public, commercial or not-for-profit sectors.

Competing interests None declared.

Patient consent for publication Obtained.

Provenance and peer review Not commissioned; externally peer reviewed.

Open access This is an open access article distributed in accordance with the Creative Commons Attribution Non Commercial (CC BY-NC 4.0) license, which permits others to distribute, remix, adapt, build upon this work non-commercially, and license their derivative works on different terms, provided the original work is properly cited and the use is non-commercial. See: http://creativecommons.org/ licenses/by-nc/4.01.

\section{ORCID iD}

Bernadeth Lyn Cal Piamonte http://orcid.org/0000-0001-9745-9384 


\section{REFERENCES}

1 Binder DK, Sonne DC, Fischbein NJ. Cranial nerves: anatomy, pathology, imaging. New York, NY: Thieme Medical Publishers, Inc, 2010: 37.

2 laconetta G, Stella L, Esposito M, et al. Tolosa-Hunt syndrome extending in the cerebello-pontine angle. Cephalalgia 2005;25:746-50.

3 Litwin CE, Leung ASO. Tolosa-Hunt syndrome presenting during pregnancy following progesterone administration. Int J Gynaecol Obstet 2017;137:340-1.

4 Levin N, Karussis D. Influence of progesterone and clomiphene on Tolosa-Hunt syndrome. Neurology 2002;59:1661-2.

5 Headache classification Committee of the International headache Society (IHS) the International classification of headache disorders, 3rd edition. Cephalalgia 2018;38:1-211.

6 Tolosa E. Periarteritic lesions of the carotid siphon with the clinical features of a carotid infraclinoidal aneurysm. J Neurol Neurosurg Psychiatry 1954;17:300-2.

7 Hunt WE, Meagher JN, LeFever HE, et al. Painful opthalmoplegia. its relation to indolent inflammation of the carvernous sinus. Neurology 1961;11:56-62.
8 Kline LB, Hoyt WF. The Tolosa-Hunt syndrome. J Neurol Neurosurg Psychiatry 2001;71:577-82.

9 Vailati A, Marena C, Comis S, et al. Hashimoto's thyroiditis in association with Tolosa Hunt syndrome: a case report. Thyroid 1993:3:125-7.

10 Granados-Reyes GM, Soriano-Redondo E, Duran-Ferreras E. [Tolosa-Hunt syndrome following traumatic eye injury]. Rev Neurol 2012;54:729-33.

11 Robinson DP, Klein SL. Pregnancy and pregnancy-associated hormones alter immune responses and disease pathogenesis. Horm Behav 2012:62:263-71.

12 Cunningham FG, Leveno KJ, Bloom SL. Williams obstetrics. 25th edn, 2018: 58-9.

13 Piccinni MP, Giudizi MG, Biagiotti R, et al. Progesterone favors the development of human Thelper cells producing Th2-type cytokines and promotes both IL-4 production and membrane CD30 expression in established Th1 cell clones. J Immunol 1995;155:128-33.

14 Koellhoffer EC, McCullough LD. The effects of estrogen in ischemic stroke. Trans/ Stroke Res 2013:4:390-401.

15 Yuan K, Wing L-YC, Lin MT. Pathogenetic roles of angiogenic factors in pyogenic granulomas in pregnancy are modulated by female sex hormones. J Periodontol 2002;73:701-8.

Copyright 2021 BMJ Publishing Group. All rights reserved. For permission to reuse any of this content visit https://www.bmj.com/company/products-services/rights-and-licensing/permissions/

BMJ Case Report Fellows may re-use this article for personal use and teaching without any further permission.

Become a Fellow of BMJ Case Reports today and you can:

- Submit as many cases as you like

- Enjoy fast sympathetic peer review and rapid publication of accepted articles

- Access all the published articles

- Re-use any of the published material for personal use and teaching without further permission

\section{Customer Service}

If you have any further queries about your subscription, please contact our customer services team on +44 (0) 2071111105 or via email at support@bmj.com.

Visit casereports.bmj.com for more articles like this and to become a Fellow 